\title{
Serial histopathological tracheal changes from prolonged intubations
}

\author{
Mohamed H. Badr El Din ${ }^{a}$, Mohamed R. Ahmeda, Adel R. Hinnis ${ }^{b}$, \\ Moustafa S. Abd El Bakya
}

aDepartments of Otolaryngology and

bPathology, Faculty of Medicine,

Suez Canal University, Ismailia, Egypt

Correspondence to Mohamed R. Ahmed, $\mathrm{MD}$, Department of Otolaryngology,

Faculty of Medicine, Suez Canal University, Ismailia, Egypt

Tel: +20 1285043825; fax: +20 663415603 e-mail: m_rifaat@hotmail.com

Received 13 September 2013 Accepted 12 December 2013

The Egyptian Journal of Otolaryngology 2014, 30:142-146

\begin{abstract}
Introduction intubations.

Materials and methods

Results among patients who were intubated for 1 week.

Conclusion

Level of evidence

Level $2 b$.

\section{Keywords:}

histopathology, intubation, trachea

Egypt J Otolaryngol 30:142-146

(c) 2014 The Egyptian Oto - Rhino - Laryngological Society

1012-5574
\end{abstract}

Prolonged tracheal intubations are usually complicated by subglottic stenosis. The aim of this study was to identify the pathological changes in the trachea due to prolonged endotracheal

A prospective study was conducted on 35 patients who were admitted to the ICUs for different periods of time and tracheostomy operation was planned for them. The part of the trachea that was removed during tracheostomy was examined histopathologically.

The most common histopathological finding was inflammation and ulceration. Fibrosis was also found with evidence of cartilage necrosis. All histopathological findings were more prevalent

Prolonged endotracheal intubations are associated with various histopathological changes ranging from erosion of the epithelium to necrosis of the cartilage and fibrosis.

\section{Introduction}

Prolonged tracheal intubations are usually associated with high incidence of stenosis [1,2]. This incidence ranged from 0.1 to $30 \%$ in prolonged intubated patients $[3,4]$. However, the utilization of high-volume, low-pressure cuff tubes in ICU remarkably reduced the incidence of postintubation stenosis $[5,6]$. However, prolonged intubations are still an important cause of acquired tracheal stenosis [3-7]. Generally, when the cuff pressure exceeds the mucosal capillary pressure $(30 \mathrm{mmHg})$, the mucosa between the cuffed tube and the underlying cartilages develops ischemia within the first few hours of intubations $[8,9]$. Long-standing ischemia leads to necrosis of the mucosa, which in turn leads to superficial ulcers and deeper ulcers with the exposure of the underlying cartilages, followed by partially or completely destructed tracheal rings with loss of structural integrity of the affected tracheal segment [7-10]. Sequels of healing occurs during any stage of this process resulting in web-like fibrosis within 3-6 weeks, leading to progressive stenosis [8-11]. Meticulous intubation technique, aggressive controlled treatment of any infections, and utilization of high-volume, low-pressure cuffed tube help to minimize the risk for stenosis [12]. Many factors are responsible for developing stenosis, including the cuff pressure, the tube size with respect to the tracheal lumen, the duration of intubations, and the movement of the tube during the period of intubations [4-13].

In addition, predisposing factors include age, female sex, the anatomical characteristics, the fragility of upper airway mucosa, the gastroesophageal reflux disease, and other risk factors including the presence of nasogastric tube [14].

Some authors believe that the causes of tracheal stenosis are acquired deficit of fibrin stabilizing factor XIII, lack of emphasis on the role of appropriate patient care in case of intubated individuals, and lack of use of sterile gloves and catheters [15].

In addition, the primary cause of intubation and the medical therapy used may have an effect on postintubation tracheal stenosis [16].

The study aimed to identify the serial histopathological tracheal changes from prolonged intubations.

\section{Materials and methods}

This was a prospective study conducted in the Department of Otolaryngology and the Histopathology Department, 
Suez Canal University Hospitals, Ismailia, Egypt, from 2007 to 2012, to evaluate the serial histopathological tracheal changes from prolonged intubations.

A total of 35 patients were admitted to the ICUs with endotracheal intubations for different day's periods (from 1 to 7 days) and subjected to tracheostomy operation. Patients with history of previous neck operation, neck masses, previous tracheostomy, and chronic tracheal illness were excluded from the study.

All patients or their relatives were subjected to history taking (duration of intubations, size of tube), local neck examination, and tracheostomy operation under sterile conditions, under local anesthesia (lignocaine and adrenaline) or general anesthesia. The strap muscles were separated vertically by blunt dissection in the midline [17]. The thyroid isthmus was identified and divided between two clamps or retracted; finally the trachea was visible [18].

The cricoid cartilage and tracheal rings were determined; then pretracheal fascia was divided, and the trachea was opened and a part of it was removed [19].

The removed part of the trachea was examined histopathologically; it was fixed in 10\% neutralbuffered formalin for $24 \mathrm{~h}$ then processed and embedded in paraffin wax blocks. Four-mm-thick serial sections were cut and stained with hematoxylineosin. In addition, Masson's trichrome stain was performed on other sections to verify fibrosis in the subepithelial region. Changes in the trachea due to endotracheal intubation were diagnosed on the basis of the identification of the histopathological criteria [20].

\section{Statistical analysis}

Gathered data were processed using SPSS version 15 (SPSS Inc., Chicago, Illinois, USA).

\section{Ethical considerations}

Written consent was obtained from all patients' firstdegree relatives, accepting to perform the tracheostomy operation and the histopathological examination. The local ethical committee in Suez Canal University Hospital approved this study.

\section{Results}

A total of 35 patients (20 male patients and 15 female patients) with a mean \pm SD age of $57.04 \pm 2.9$ years were subjected to tracheostomy operation after tracheal intubations in the ICU to obtain the serial histopathological tracheal changes.

In all, $74 \%$ patients were admitted to ICU because of stroke, $13 \%$ because of traumatic brain insult, $9 \%$ because of COPD exacerbation and respiratory failure, and $4 \%$ because of status epilepticus and bulbar palsy.

Patients were divided according to the duration of intubation and the tracheostomy operation from day 1 to day 7 depending on several factors, such as the patients general condition, the Glasgow Coma Scale, and the patients' condition prognosis, to obtain the serial histopathological tracheal changes with a set of five patients on similar day to obtain near-similar groups in statistical analysis.

All of the tracheostomies were temporal and removed according to patients' improvement clinically.

In all, $76 \%$ of patients used tube sized $7.5 \mathrm{~mm}, 12 \%$ used size $8 \mathrm{~mm}, 8 \%$ used size $7 \mathrm{~mm}$, and $4 \%$ used size $6 \mathrm{~mm}$

On the first day of the tracheostomy, there was inflammation, which occurred also on the second day with erosion of the epithelium. On the third day, atrophy of and damage to the submucosal glands was observed, which extended also to the fourth day with epithelial ulceration. On the fifth day, metaplasia was evident with starting of cartilage necrosis, which was completed on the sixth day with appearance of the fibrous tissue, and fibrosis was evident on the seventh day (Table 1 and Figs. 1-4).

Table 1 Distribution of the studied patients according to histopathological findings

\begin{tabular}{lcccccc}
\hline Days & Inflammation & $\begin{array}{c}\text { Erosion of the } \\
\text { epithelium }\end{array}$ & $\begin{array}{c}\text { Atrophy and damage of the } \\
\text { submucosal glands }\end{array}$ & Ulceration & $\begin{array}{c}\text { Metaplasia } \\
\text { Cartilage } \\
\text { necrosis }\end{array}$ & $\begin{array}{c}\text { Fibrosis } \\
\text { First }\end{array}$ \\
Second & + & ++ & + & & & \\
Third & +++ & ++ & ++ & & \\
Fourth & & & +++ & ++ & & \\
Fifth & & & & & + \\
Sixth & & & & + & ++ \\
Seventh & & & & & + \\
\hline
\end{tabular}

+ mild; ++, moderate; +++, severe. 


\section{Figure 1}

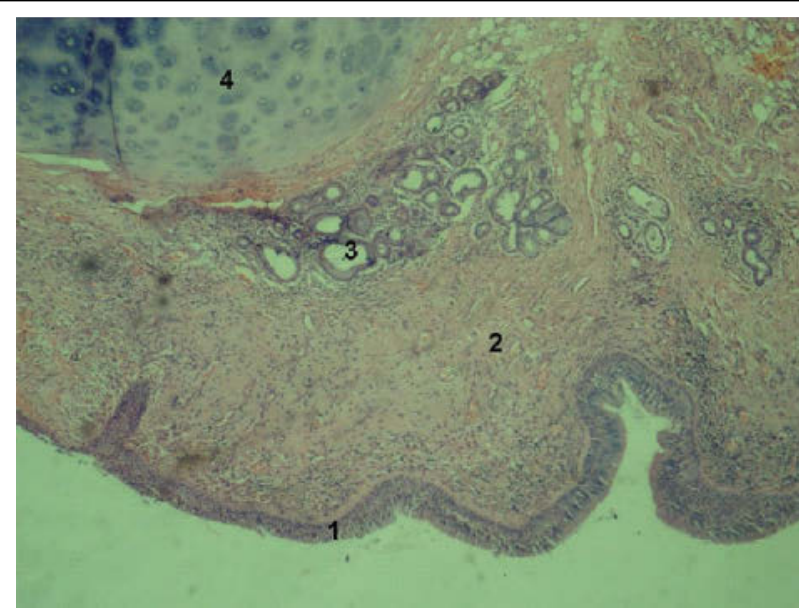

Infiltration of the subepithelial connective tissue and around the mucus glands by inflammatory cells $(\mathrm{H} \& \mathrm{E}, \times 40)$. $1=$ epithelium, $2=$ connective tissue, $3=$ seromucinous glands, and $4=$ tracheal cartilage .

\section{Figure 3}

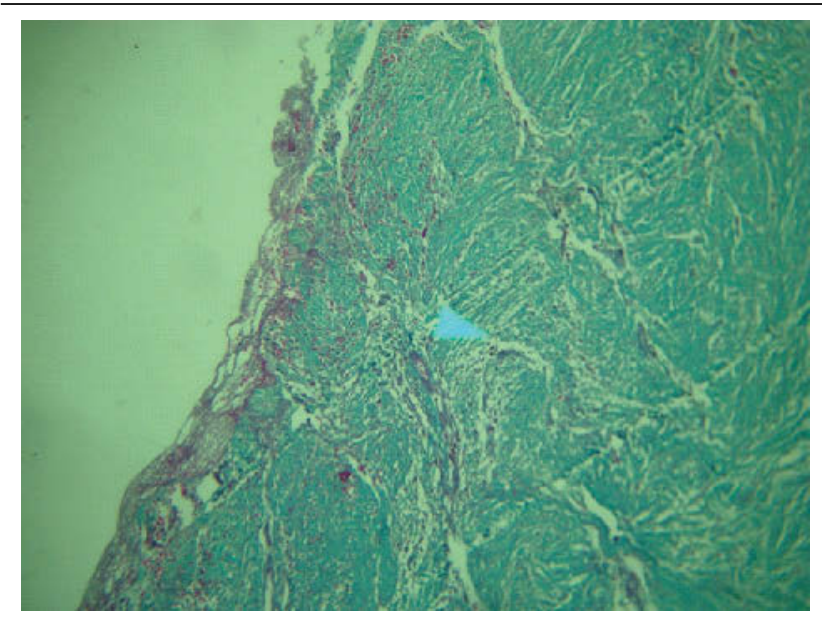

Ulceration, atrophy of glands, and marked fibrosis in lamina propria (Masson's trichrome, $\times 100$ ).

Correlation between tube size and histopathological findings showed that patients with tube size $6 \mathrm{~mm}$ showed inflammation and erosion of the epithelium, with tube size $7 \mathrm{~mm}$ showed inflammation, erosion of the epithelium, and ulceration, with tube size $7.5 \mathrm{~mm}$ showed atrophy of the submucosal glands, necrosis of the cartilage, and metaplasia, and with tube size $8 \mathrm{~mm}$ showed metaplasia, necrosis of the cartilage, and fibrosis.

\section{Discussion}

Increase in the number of patients requiring intensive care and airway support has been associated with significant short-term and long-term morbidity [3].
Figure 2

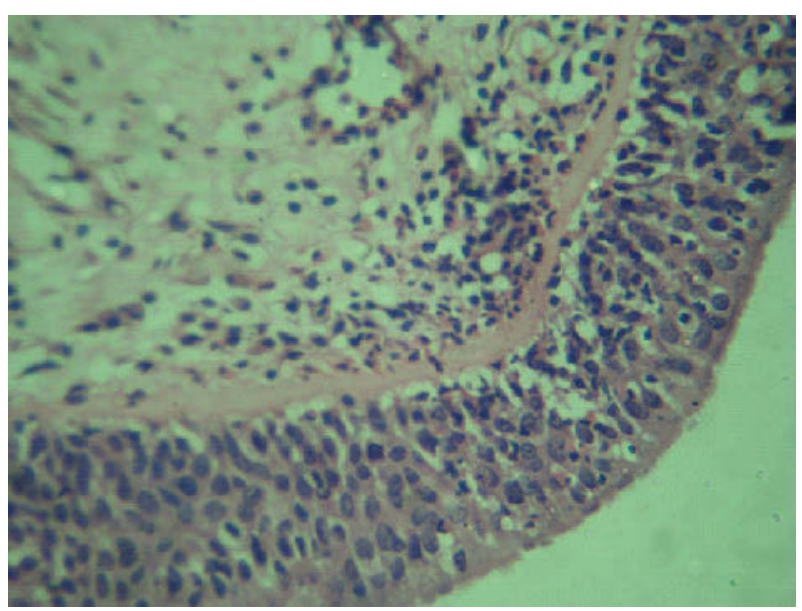

Edema, congestion, and infiltration of lamina propria by inflammatory cells; inflammatory cells are also attacking the epithelium (H\&E, ×200).

\section{Figure 4}

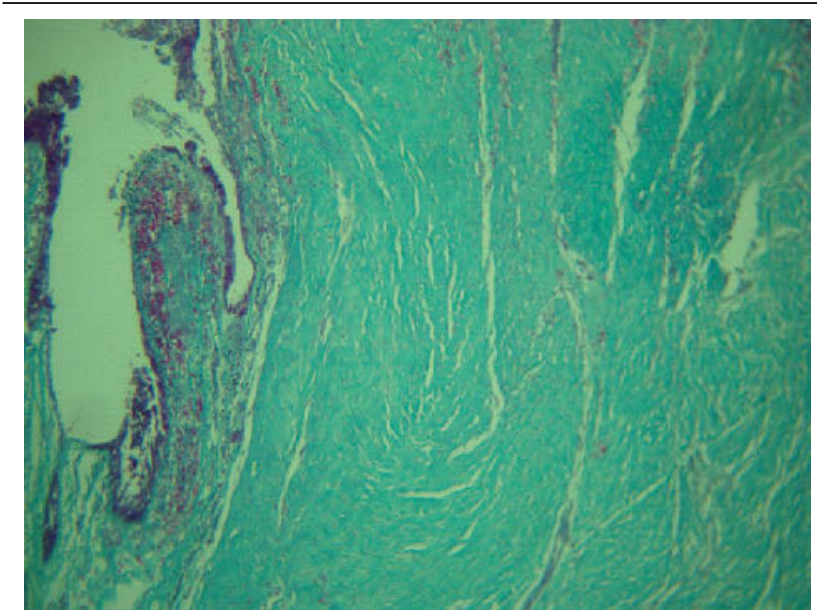

Erosion of the epithelium with subepithelial dense fibrosis (Masson's trichrome, $\times 100$ )

Many authors recommended tracheostomy for patients with endotracheal intubations more than 3 days to avoid long-term complications [21].

However, some authors mentioned severe injury to patients in whom tracheostomy was recommended after $17 \mathrm{~h}$ of intubation in adults [22].

The etiology of postintubation tracheal stenosis is probed in numerous publications, but to date has not been fully elucidated. Various authors consider mechanical damage to the tracheal mucosa, and especially compression with ischemia-associated necrosis of the stenotic segment to be the main cause of stenosis. Nevertheless, also such issues are taken into consideration as local infections, low blood pressure during the period of intubation, steroid administration, sensitivity of the patient to the used intubation 
materials, and chemical agents used to sterilize the intubation tube, as well as an individual idiosyncratic reaction [12].

To explain the etiology of tracheal stenosis, numerous experimental studies have been carried out in animal models [23], wherein the investigators have observed similarities between lesions encountered in animals (dogs and rabbits) and in humans [23,24]. In our study, many patients showed the presence of tracheal fibrosis and possible stenosis on the seventh day. This is in agreement with the study by Stauffer et al. [3], who reported that $19 \%$ of the patients who had translaryngeal intubation develop tracheal stenosis.

Fibrosis is probably induced by migration of fibroblasts to the site of injury with proliferation and secretion of extracellular matrix such as fibronectin and proteoglycan; with further healing, there is increase in the amount of type 1 collagen and decrease in the number of active fibroblasts and new vessels $[25,26]$. This leads to the formation of fibrous scar formed of inactive spindleshaped fibroblasts, dense collagen bundles, fragments of elastic tissue, and relatively few vessels [27].

In early postintubation tracheal lesions, one can observe mostly the mucosa being turned ischemic, as well as edema, congestion, hemorrhages, and traces of fibrinous exudate. In the majority of cases, these lesions promptly regress within $12-48 \mathrm{~h}$. According to Patil et $a l$. , they are the most pronounced in the first week and subsequently undergo gradual regression [28].

In our study, the most common pathological finding was inflammation in the area of mucosa, submucosa, and around the mucus glands, ulceration, erosion of the epithelium, atrophy of submucosal glands, and evidence of cartilage necrosis.

The occurrence of inflammation after tracheal intubations is induced by pressure injury from the tube that stimulates the inflammatory reaction. Inflammation is usually associated with congestion and soft tissue edema within hours of intubations $[9,17]$.

This could be attributed to the impaired mucociliary clearance mechanism due to the presence of the tube, and stasis of secretions due to squamous metaplasia [29]. Other causes of inflammation could be the trauma from suction, bacterial infection, and effect of drugs [12].

Stauffer et al. [3] found mucosal ulcers at the level of the tracheal cuff in $15 \%$ patients. Priyanka's study demonstrates that the development of mucosal epithelium damage can occur within an hour of endotracheal intubation and that the degree of ulceration tends to be proportional to the duration of intubations [27].
Some patients can also develop a specific form of ulceration, ring-shaped tracheitis, which places them at a high risk for subsequent tracheal stenosis. Finally, significant gastroesophageal reflux has been demonstrated in intubated patients in the operating room and in the ICU, with up to a $40 \%$ incidence [30].

In our study, there was an evidence of squamous metaplasia. Metaplasia is a reversible condition in which the columnar epithelium, which is the normal type for the trachea, is replaced by stratified squamous epithelium [25].

Squamous metaplasia appeared on the tracheal mucosa subjected to the trauma of the cuff and the tube [12-22]. The regions of ciliated or abraded pseudostratified epithelium would be found between the zones of squamous metaplasia. As the duration of intubation progressed, these squamous metaplastic regions became confluent.

The creation of an intratracheal zone of squamous epithelium in the midst of the ciliated epithelium can be expected to impair the removal of these secretions from the airways. This, in turn, may significantly increase the frequency and duration of acute and chronic infections. Squamous metaplasia and pressure of the tube impairing the mucociliary clearance may explain the increase in the level of inflammation in our study [12-22]. Priyanka found microscopic evidence of bacterial infection in every larynx or trachea intubated for more than $48 \mathrm{~h} \mathrm{[27].}$

\section{Conclusion}

Endotracheal intubations are associated with various histopathological changes ranging from inflammation of the epithelium to necrosis of the cartilage and fibrosis. The longer duration of intubation may be associated with higher incidence of these complications.

\section{Acknowledgements \\ Conflicts of interest}

There are no conflicts of interest.

\section{References}

1 Rudert H. Rare injuries of the larynx following endotracheal intubation. Vocal cord paresis, distortion and dislocation of the cricoarytenoid joints. HNO 1984; 32:393-398.

2 Rieger A, Hass I, Gross M, Gramm HJ, Eyrich K. Intubation trauma of the larynx - a literature review with special reference to arytenoid cartilage dislocation [article in German]. Anasthesiol Intensivmed Notfallmed Schmerzther 1996; 31:281-287. 
3 Stauffer JL, Olson DE, Petty TL. Complications and consequences of endotracheal intubation and tracheotomy. A prospective study of 150 critically ill adult patients. Am J Med 1981; 70:65-76.

4 Pearson FG, Andrews MJ. Detection and management of tracheal stenosis following cuffed tube tracheostomy. Ann Thorac Surg 1971; 12: 359-374.

5 Spittle CS, Beavis SE. Post-intubation tracheal stenosis. Hosp Med 2001; 62:54.

6 Ahmad I, Pahor AL. Post-intubation tracheal stenosis. Hosp Med 2000 61:508-509.

7 Bishop MJ, Weymuller EA, Fink BR. Laryngeal effects of prolonged intubation. Anesth Analg 1984; 63:335-342.

8 Spittle N, McCluskey A. Lesson of the week: tracheal stenosis after intubation. Br Med J 2000; 321:1000-1002.

9 Weymuller EA Jr. Laryngeal injury from prolonged endotracheal intubation. Laryngoscope 1988; 98:1-15.

10 Wain JC. Postintubation tracheal stenosis. Chest Surg Clin N Am 2003 13:231-246.

11 Grillo C. In: Shields W, Lo Cicero J, Ponn B, editors. Management of neoplastic diseases of the trachea. General thoracic surgery. 5th ed. Philadelphia: Lippincott Williams \& Wilkins; 2000. 1:885-897.

12 Obrebowski A, Wojnowski W. Hoarseness resulting from post-intubation arytenoid cartilage subluxation in an 11-year-old girl. Otolaryngol Pol 1998; 52:223-226.

13 Freitag L, Ernst A, Unger M, Kovitz K, Marquette $\mathrm{CH}$. A proposed classification system of central airway stenosis. Eur Respir J 2007; 30:7-12.

14 Maronian NC, Waugh $\mathrm{P}$, Azadeh $\mathrm{H}$, Hillel A. Association of laryngopharyngeal reflux disease and subglottic stenosis. Ann Otol Rhino Laryngol 2001; 110:606-612.

15 Balluch $\mathrm{H}$. Aetiology of tracheal stenoses after long-term intubation of patients with multiple injuries. HNO 1983; 31:395-398.

16 Fishman $\mathrm{NH}$, Dedo $\mathrm{HH}$, Hamilton WK, Hinchcliffe WA, Roe BB Postintubation tracheal stenosis. Ann Thorac Surg 1969; 8:47-56.

17 Ahmet B, Ayşen TŞ, Mehmet K, Tülin DY, Ömer SB, Tamer K. The high risk of postintubation tracheal stenosis in patients intubated for organophosphate poisoning. Göğüs Kalp Damar Cerrahisi Dergisi 2012; 20:567-571.

18 Stell M. In: Ransome J, Holden H, Bull R, editors. Tracheotomy and tracheostomy. Recent advances in otolaryngology. Edinburgh: Churchill Livingstone; 1973. 275-294.

19 Wood DE, Mathisen DJ. Late complications of tracheotomy. Clin Chest Med 1991; 12:597-609.

20 Heffner JE. Timing of tracheotomy in mechanically ventilated patients. Am Rev Respir Dis 1993; 147:768-771.

21 Bercstorm R, Lindholm E. Postmortem studies of damage following prolonged endotracheal intubation $\&$ in a number of cases secondary tracheotomy. Acta Anaesthesiol Scand 1960; 13:81-131.

22 Carrat X, Pescio P, Verhulst J, Devars F, Duroux S, Traissac L. Postintubation interarytenoid adhesion. Ann Otol Rhinol Laryngol 2000; 109:736-740.

23 Liu J, Zhang X, Gong W, Li S, Wang F, Fu S, et al. Correlations between controlled endotracheal tube cuff pressure and postprocedural complications: a multicenter study. Anesth Analg 2010; 111: 1133-1137.

24 Zagalo C, Grande NR, Dos Santos JM, Monteiro E, Brito J, Aguas AP. Tracheal transplantation: cytological changes studied by scanning and transmission electron microscopy in the rabbit. Laryngoscope 2001; 111:657-662.

25 Zagalo C, Santiago N, Grande N, Martins Dos Santos J, Brito J, Águas A. Morphology of trachea in benign human tracheal stenosis: a clinicopathological study of 20 patients undergoing surgery. Surg Radiol Anat 2002; 24:160-168.

26 Duynstee L, Krijger R, Monnier P. Subglottic stenosis after endotrachea intubation in infants and children: result of wound healing processes. Int $J$ Pediatr Otorhinolaryngol 2002; 62:1-9.

27 Priyanka GP, Ravi J, Soumi MC, Thakkar JM, Patel BM. Tracheal Granuloma as an incidental Finding During Endotracheal Intubation, GMJ (Gujarat Medical Journal) 2012; 67:124.

28 Patil PG, Jain R, Chaudhuri SM, Thakkar JM, Patel BM. Tracheal granuloma as an incidental finding during endotracheal intubation: case report. Gujarat Med J. 2012; 67:125.

29 Debain JJ, Le Brigand H, Binet JP, Pottemain M, Freyss G, Bonhomme F. Some difficulties and accidents of prolonged tracheal intubation: study of combined results in a cardiopulmonary department and in a medical resuscitation department. Ann Otolaryngol Chir Cervicofaciale 1968; 85:379-386

30 Ham AW, Cormack DH. Histology. 5th ed., Pitman Medical Publishing Co. Ltd., London. 1979; 476-501. 